\title{
Influence of head and linear growth on the development of malocclusion at six years of age: a cohort study
}

\section{Manuelly Pereira de Morais Santos CAMPOS(a) \\ Paula Andréa de Melo VALENÇA ${ }^{(b)}$ \\ Genivaldo Moura da SILVA(c) \\ Marília de Carvalho LIMA ${ }^{\text {(d) }}$ \\ Silvia Regina JAMELLI(b) \\ Paulo Sávio Angeiras de GÓES(e)}

\footnotetext{
(a) Universidade Federal de Pernambuco UFPE, Dental Program, Recife, PE, Brazil.

(b) Universidade Federal de Pernambuco UFPB, Department of Clinical and Preventive Dentistry, Recife, PE, Brazil.
}

(c) Universidade Federal de Pernambuco - UFPE, Child and Adolescent Health Program, Recife, PE, Brazil.

(d) Universidade Federal de Pernambuco UFPE, Maternal-infant Department, Recife, PE, Brazil.

(e) Universidade Federal de Pernambuco UFPE, Department of Social Dentistry, Recife, PE, Brazil.

Declaration of Interests: The authors certify that they have no commercial or associative interest that represents a conflict of interest in connection with the manuscript.

\section{Corresponding Author:}

Manuelly Pereira de Morais Santos

E-mail: manuellyp@hotmail.com

https://doi.org/10.1590/1807-3107bor-2018.vol32.0098

Submitted: March 28, 2017

Accepted for publication: July 24, 2018

Last revision: August 22, 2018

\begin{abstract}
The aim of this article was to evaluate the influence of biological and sociobehavioral factors on the development of malocclusions in children. This is a cross-sectional study nested in a cohort of 350 children who participated in a community intervention study. After six years, an active search identified 290 children with occlusal abnormalities. Socioeconomic status, linear growth, and nutritional status of the child at birth and at the time of measurement, as well as dietary and sucking habits, were investigated. Malocclusions were evaluated across three spatial planes - anteroposterior, vertical, and transverse. The prevalence of these anomalies was $64.5 \%$, primarily in the anteroposterior plane. The logistic regression analysis revealed that pacifier use for 60 months or more, stunting as measured at age six, and reduced gain in head circumference from birth to six years of age, were significantly associated with the development of malocclusion in childhood. Head circumference and linear growth are associated with occlusal anomalies in infants, independent of pacifier sucking.
\end{abstract}

Keywords: Growth and Development; Child, Preschool; Malocclusion; Oral Health.

\section{Introduction}

Malocclusions have been described as being caused by both geneticevolutionary factors, which may influence the development of the craniofacial complex and of occlusal anomalies, ${ }^{1,2}$ and by sucking habits, which may favor the development of these abnormalities. ${ }^{3,4}$ According to Nahás-Scocate et al., ${ }^{5}$ the key to determine the etiology of malocclusions is to assess the preponderant effect of each factor in particular. The prevalence of this condition in the Brazilian child population has increased progressively, reaching the alarming rate of about $50 \%$ of preschoolers. ${ }^{6,7}$

Some studies ${ }^{8,9}$ have reported that sucking habits, depending on their intensity, duration and frequency, can influence facial growth, and thus affect structures, functions, and orofacial and occlusal relationships. These habits are described as nutritive (breast- or bottle-feeding) or nonnutritive (finger- or pacifier-sucking).

The literature has also shown that nutritional deficiency during child growth and development causes a delay in the ossification centers, and may contribute to poor skeletal and dental formations. ${ }^{10,11}$ Moreover, the 
modern human skull and face have become smaller with evolution, especially in terms of anteroposterior length and vertical height. ${ }^{12}$

At the individual level, malocclusion can cause severe functional and cosmetic deficiencies that can interfere with quality of life, leading to impaired social interactions and psychological well-being. ${ }^{8}$ Moreover, such occlusal anomalies are burdensome to public services, since they may require long-term, interdisciplinary treatments, as well as ongoing assessment and monitoring.

Since human potentials are developed at childhood, disorders at this time may be responsible for serious consequences to individuals and communities. ${ }^{8}$ Accordingly, the previous understanding of the factors that may compromise the proper development of the human being is important for preventing or intervening in early-life disorders.

Thus, the aim of this study was to examine the relationship between dental malocclusion and the factors of feeding practices, sucking habits and skeletal structure.

\section{Methodology}

\section{Study site}

The study was conducted in the cities of Palmares, Catende, Água Preta, and Joaquim Nabuco, all located about $120 \mathrm{~km}$ from the capital city of Recife, state of Pernambuco, in a coastal plain forest region to the south of the state, called Zona da Mata. The geographical, socioeconomic, demographic, and health aspects of these cities are similar. Since the agricultural subsistence in the region is sugarcane as a monocrop, the region relies mainly on the cultivation and processing of sugarcane and on commerce.

\section{Study design and sample}

This cross-sectional study was nested in a cohort of 350 children recruited at birth by parental indication of intention, and aims to promote awareness of the importance to increase the duration of exclusive breastfeeding and to guide in introducing a complementary diet ${ }^{13}$. The sample size calculation was based on a 1:1 ratio between exposed and nonexposed malocclusion. A prevalence of $30 \%$ and an
OR of 1.5 was detected. The study children were monitored monthly at home during the first 12 months of life. There was a $7 \%$ loss. The present study was conducted by questioning the cohort members actively in their homes, to assess malocclusion at six years of age. Two hundred and ninety-three mother-child pairs were called, and the loss at this stage was $16.3 \%$. Of these, three children did not meet the inclusion criteria and were excluded from the study. Thus, a total of 290 mother-child pairs participated. The exclusion criteria were children undergoing some type of orthodontic treatment; children with dental anomalies in shape, number and/or size; children with extensive carious lesions; and children with cleft lip and palate.

\section{Assessment of malocclusion}

Malocclusion was assessed by clinical examination. At the time of the examination, the mandible was guided into centric occlusion. Children who did not present any abnormalities were considered as having a normal occlusion.

The presence of dental malocclusions was assessed in reference to three spatial planes (anteroposterior, vertical and transverse); the child was considered to have an occlusal anomaly when an alteration was observed in at least one of these planes. The anteroposterior plane was assessed according to the relationship between the deciduous canines, ${ }^{14}$ and the terminal plane, according to the deciduous second molars ${ }^{15}$ and/or to the relationship between permanent first molars. ${ }^{16}$ The presence of anterior open bite was analyzed to determine the vertical plane, and the presence of crossbite, to determine the transverse plane.

Anterior open bite (AOB) was defined according to Foster and Hamilton, ${ }^{14}$ i.e. when the incisal edges of the mandibular central incisors are below the level of the incisal edges of the maxillary central incisors, resulting in the lack of occlusal contact. Crossbite (CB) was defined as follows: when the teeth of the upper arch are palatally displaced in relation to those of the lower arch, in either the posterior (unilateral/bilateral) or the anterior segment, or in both segments in one or more teeth. Accordingly, both dental and skeletal malocclusions were assessed in the present study. 


\section{Assessment of nutritional status at birth and at time of measurement}

Birth weight was assessed with subjects wearing no clothes, by using a digital baby weighing scale (Model 15/2B Filizola). At the age of six, height was measured using a stadiometer (Alturexata ${ }^{\circledR}$ ); the standard recommended by $\mathrm{WHO}^{17}$ was adopted. Height was measured in duplicate by adopting the average of the measurements. If the difference was greater than $0.5 \mathrm{~cm}$, a third measurement was taken and the average of the two measurements nearest to 5.0 was adopted. All the children were evaluated by the anthropometrists of the Department of Nutrition of the Federal University of Pernambuco, following the guidelines of the Manual of Anthropometry of the General Coordination for Food and Nutrition issued by the Ministry of Health (CGAN/MS).

The nutritional status both at birth and at the time of measurement was assessed by the height/ age ratio, as expressed in the Z-score index. The reference standard used was that recommended by the $\mathrm{WHO}^{17}$ with the following cut-off points: < -1 Z-score = malnutrition / malnutrition risk, $\geq-1$ Z-score $=$ low weight.

Cephalic perimeter $(\mathrm{CP})$ at birth and at the age of six was measured using an inelastic tape with an accuracy rate of $1 \mathrm{~mm}$, observing the standard procedure. ${ }^{17}$ A cut-off point of -1 SD was adopted in relation to the children's mean head circumference. The gain in head circumference was also observed by obtaining the difference between the values of this measurement at six years of age and at birth. A cut-off point of $-1 \mathrm{SD}$ in relation to the mean gain in head circumference was also adopted.

\section{Feeding habits}

Feeding habits were investigated in the first six months of life (type of breastfeeding at six months and bottle-feeding). The WHO criteria (2007) were adopted in defining the types of breastfeeding: exclusive breastfeeding if the child received only breast milk without the addition of water or other liquids/solids; predominant breastfeeding if the child received breast milk and water, juice or tea; partial breastfeeding, if the child received breast milk and other kinds of milk or other foods; and never breastfed if the child received no breast milk. Children who were exclusively or predominantly breastfed were grouped into a single category labeled exclusive/ predominant breastfeeding.

Lastly, mothers were asked about the use of pacifiers at six months and six years of age. If the child did not use a pacifier at the age of six years, the mother was asked about the duration of this sucking habit; they were also asked about finger-sucking and its duration.

\section{Standardization of techniques}

The standardization and the training to ensure quality control of the diagnostic criteria of malocclusion were performed by repeating the dental examination in a subsample of 30 children during the pilot study. Intrarater agreement was assessed by obtaining a kappa index of 0.98 .

\section{Statistical analysis}

A multivariate logistic regression was conducted to check the adjusted effect of the explanatory variables in establishing the malocclusions. Variables with $\mathrm{p}$ $\leq 0.20$ in the bivariate analyses were selected to be introduced into the multivariate logistic regression analyses.

Odds ratio (OR), and its respective confidence interval of $95 \%$, was used as the measure of association. The selected reference category to estimate unadjusted and adjusted OR was that which presented a lower risk of malocclusion. The chi-square was used considering $\mathrm{p} \leq 0.05$ as statistically significant.

The hierarchical approach using the enter method was employed. Thus, four regression models were developed. In the first, socioeconomic variables (home ceiling features and owners of a refrigerator) were introduced. In Model 2, the type of breastfeeding at six months of life was entered. In Model 3, the children's nutritional status at six years of age, evaluated by the height/age (H/A) index, and the gain in head circumference at six years old, were included. Finally, in Model 4, bottle-feeding at 6 months of age, and the duration of pacifier use were included. The variables that remained significant at the level of $20 \%$ were kept in the model and were included in the adjustment of the next level. Once selected at a certain level, the 
variables remained in the subsequent models, even if their 'significance' was lost with the inclusion of variables at a lower hierarchical level. Data analysis was performed with SPSS software (Statistical Package for Social Sciences) version 18.

\section{Ethical aspects}

This study was approved by the Human Research Ethics Committee of the Science Center of the Federal University of Pernambuco, CAAE No. 0245.0.172.00007. In addition, mothers were informed about the objectives and procedures of the study, and written consent was obtained.

\section{Results}

The sample was composed of 290 children with a slight male predominance. Although the income of more than half of the families was lower than or equal to half of the minimum wage, $63 \%$ had access to services such as water supply, garbage collection, and electricity. Regarding maternal education, only $38.3 \%$ of the mothers attended school for 9 years or more (Table 1).
In this study, 187 children presented some type of malocclusion in the anteroposterior, vertical or transverse dimension; thus, the prevalence of this anomaly was $64.5 \%$, predominantly in the anteroposterior plane (38.3\%) (Figure), and 20.3\% of the children presented occlusal abnormalities in more than one spatial plane. The AOB and CB were diagnosed in approximately $15 \%$ of the sample.

The prevalence of exclusive/predominant breastfeeding at six months was $25.9 \%$ (Table 2), and pacifier use at this age was observed in $62.4 \%$ of the children. At six years of age, a high percentage of pacifier use was observed, with a prevalence of pacifier use over finger sucking (59\% vs. $11.4 \%$ ).

A higher percentage of children with appropriate anthropometric measurements at birth (weight, height, and head circumference) was observed. However, the bivariate analysis showed that children with restricted $\mathrm{H} / \mathrm{A}$ at six years of age and a lower gain in $\mathrm{CP}$ over these years showed significant association with the different types of malocclusion (Table 3).

Bottle-feeding was predominant at six months of life, and $68.8 \%$ of the sample had some type of

Table 1. Association between malocclusion in children at six years old and sociodemographic status, in the Zona da Mata forest region of southern Pernambuco, Brazil, 2008 ( $n=290)$.

\begin{tabular}{|c|c|c|c|c|c|c|}
\hline \multirow{2}{*}{ Variable } & \multirow{2}{*}{$n$} & \multirow{2}{*}{$\%$} & \multicolumn{4}{|c|}{ Malocclusions } \\
\hline & & & Yes (\%) & n (\%) & OR $(95 \% \mid C)$ & $p$-value* \\
\hline \multicolumn{7}{|c|}{ Per capita family income (MW) } \\
\hline$\leq 0.25$ & 130 & 44.8 & $88(67.7)$ & 42 (32.3) & $1.21(0.64-2.30)$ & 0.56 \\
\hline $0.26-0.50$ & 100 & 34.5 & $61(61.0)$ & $39(39.0)$ & $0.91(0.47-5)$ & \\
\hline$>0.51$ & 60 & 20.7 & $38(63.3)$ & $22(36.7)$ & 1.00 & \\
\hline \multicolumn{7}{|c|}{ Mother's education (years) } \\
\hline 0 a 3 & 58 & 20.0 & $40(69.0)$ & $18(31.0)$ & $1.35(0.68-2.66)$ & 0.68 \\
\hline 4 a 8 & 121 & 41.7 & $78(64.5)$ & $43(35.5)$ & $1.10(0.65-1.88)$ & \\
\hline$\geq 9$ & 111 & 38.3 & $69(62.2)$ & $42(37.8)$ & 1.00 & \\
\hline \multicolumn{7}{|l|}{ Ceiling features } \\
\hline Concrete & 59 & 20.3 & $39(66.1)$ & $20(33.9)$ & $2.05(0.91-4.63)$ & 0.07 \\
\hline Clay & 190 & 65.5 & $128(67.4)$ & $62(32.6)$ & $2.17(1.09-4.30)$ & \\
\hline Asbestos cement & 41 & 14.2 & $20(48.8)$ & $21(51.2)$ & 1.00 & \\
\hline \multicolumn{7}{|c|}{ Household - refrigerator } \\
\hline No & 61 & 21.1 & $45(73.8)$ & $16(26.2)$ & $1.72(0.92-3.23)$ & 0.09 \\
\hline Yes & 229 & 78.9 & $142(62.0)$ & 87 (38.0) & 1.00 & \\
\hline
\end{tabular}

*Pearson Chi-square test; MW: Minimum wage. 


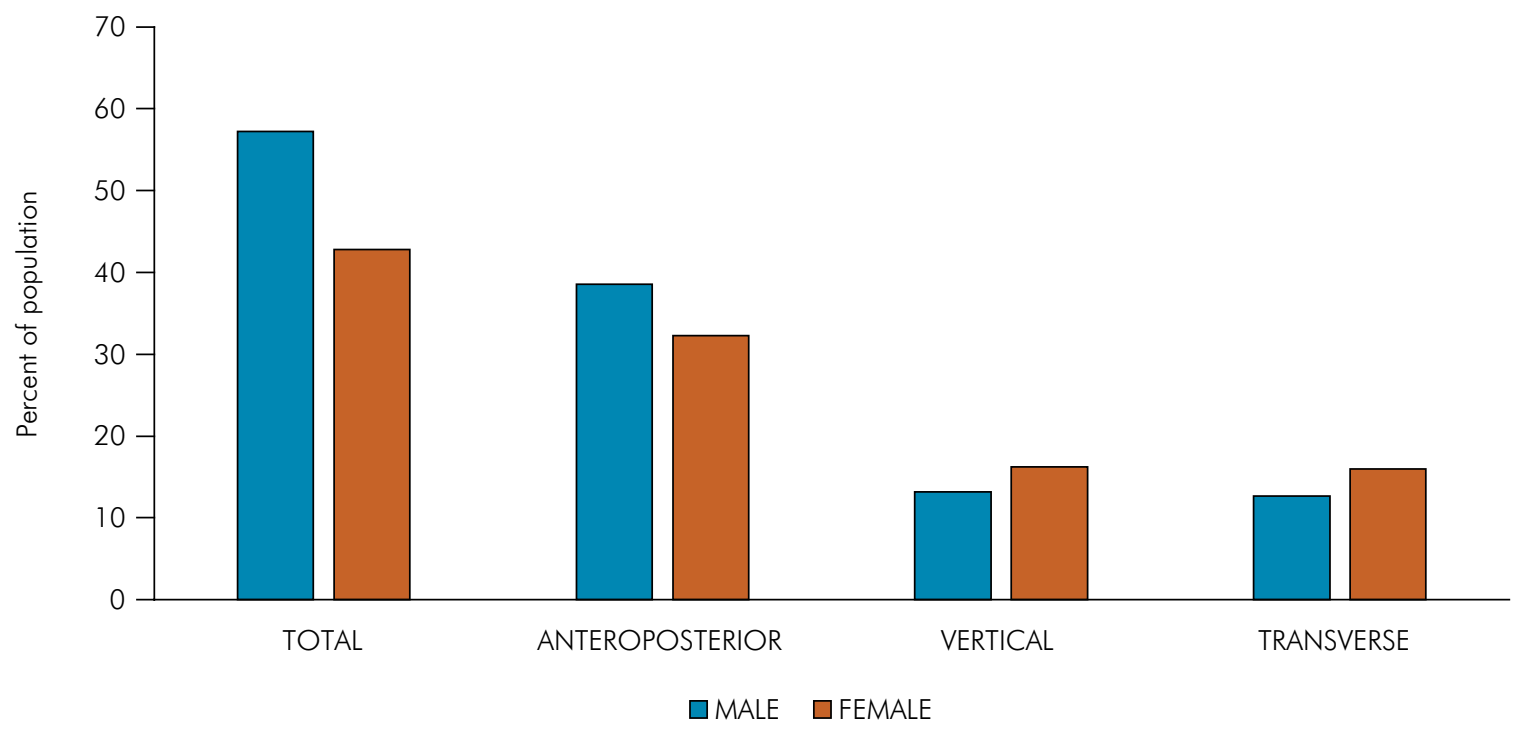

Figure. Prevalence of malocclusion according to sex among members of the population up to six years of age (adapted from Buschang). ${ }^{18}$

Table 2. Association between malocclusion in children at six years old and sucking habits, in the Zona da Mata forest region of southern Pernambuco, Brazil, 2008 ( $n=290$ ).

\begin{tabular}{|c|c|c|c|c|c|c|}
\hline \multirow{2}{*}{ Variable } & \multirow{2}{*}{$\mathrm{n}$} & \multirow{2}{*}{$\%$} & \multicolumn{4}{|c|}{ Malocclusions } \\
\hline & & & Yes (\%) & No (\%) & OR $(95 \% \mid C)$ & p-value* \\
\hline \multicolumn{7}{|l|}{ Breastfeeding (6 months) } \\
\hline None & 147 & 50.7 & $105(71.4)$ & $42(28.6)$ & 2.15 (1.20-3.83) & 0.03 \\
\hline Partial & 68 & 23.4 & $44(64.7)$ & $24(35.3)$ & $1.56(0.79-3.09)$ & \\
\hline Exclusive/Predominant & 75 & 25.9 & $40(53.3)$ & $35(46.7)$ & 1.00 & \\
\hline \multicolumn{7}{|l|}{ Bottle use (6 months) } \\
\hline Yes & 226 & 77.9 & $155(68.8)$ & $71(31.4)$ & $2.18(12.4-3.84)$ & 0.01 \\
\hline No & 64 & 22.1 & $32(50.0)$ & $32(500)$ & 1.00 & \\
\hline \multicolumn{7}{|l|}{ Pacifier use (6 years) } \\
\hline Yes & 171 & 58.9 & $121(70.8)$ & $50(29.2)$ & $1.94(1.19-3.17)$ & 0.01 \\
\hline No & 119 & 41.1 & $66(55.5)$ & $53(44.5)$ & 1.00 & \\
\hline \multicolumn{7}{|l|}{ Pacifier use duration } \\
\hline No & 119 & 41.0 & $66(55.5)$ & $53(44.5)$ & 1.00 & 0.00 \\
\hline$<60$ months & 111 & 38.3 & $69(62.2)$ & $42(37.8)$ & 1.32 (0.78-2.23) & \\
\hline$\geq 60$ months & 60 & 20.7 & $52(86.6)$ & $8(13.4)$ & $5.20(2.28-11.94)$ & \\
\hline \multicolumn{7}{|l|}{ Finger sucking (6 years) } \\
\hline Yes & 33 & 11.4 & $20(60.6)$ & $13(39.4)$ & $0.83(0.39-1.74)$ & 0.62 \\
\hline No & 257 & 88.6 & $167(65.0)$ & $90(35.0)$ & 1.00 & \\
\hline
\end{tabular}

*Pearson Chi-square test.

malocclusion, showing a significant association between these two variables $(p=0.01)$. However, when this association was influenced by the child's biological factors (CP and height) and by pacifier use for 60 months or more, it lost significance $(\mathrm{p}=0.20)($ Table 4$)$.

Although no statistically significant association was found in the multivariate analysis between 
Influence of head and linear growth on the development of malocclusion at six years of age: a cohort study

Table 3. Association between malocclusion and gender and anthropometric measurements in children at six years old, in the Zona da Mata forest region of southern Pernambuco, Brazil, 2008 ( $n=290$ ).

\begin{tabular}{|c|c|c|c|c|c|c|}
\hline \multirow{2}{*}{ Variable } & \multirow{2}{*}{$\mathrm{n}$} & \multirow{2}{*}{$\%$} & \multicolumn{4}{|c|}{ Malocclusions } \\
\hline & & & Yes (\%) & No (\%) & OR $(95 \% \mathrm{Cl})$ & p-value* \\
\hline \multicolumn{7}{|l|}{ Gender } \\
\hline Male & 166 & 57.3 & $107(64.5)$ & $59(35.5)$ & $0.99(061-1.62)$ & 0.99 \\
\hline Female & 124 & 42.7 & $80(64.5)$ & $44(35.5)$ & 1.00 & \\
\hline \multicolumn{7}{|l|}{ Birth weight (g) } \\
\hline$\leq 2500$ & 24 & 8.3 & $17(70.8)$ & $7(29.2)$ & $1.37(0.55-3.42)$ & 0.50 \\
\hline$>2500$ & 266 & 91.7 & $170(63.9)$ & $96(36.1)$ & 1.00 & \\
\hline \multicolumn{7}{|l|}{$\mathrm{CP}$ at birth $(\mathrm{cm})$} \\
\hline$<33$ & 42 & 14.5 & $29(69.0)$ & $13(31.0)$ & $1.27(0.63-2.57)$ & 0.50 \\
\hline$\geq 33$ & 248 & 54.5 & $158(63.7)$ & $90(36.3)$ & 1.00 & \\
\hline \multicolumn{7}{|c|}{$\mathrm{CP}$ at 6 years $(\mathrm{cm})$} \\
\hline$<50$ & 44 & 15.2 & $34(77.3)$ & $10(22.7)$ & $2.07(0.98-4.38)$ & 0.05 \\
\hline$\geq 50$ & 246 & 84.8 & $153(62.2)$ & $93(37.8)$ & 1.00 & \\
\hline \multicolumn{7}{|c|}{ Gain in CP (0 to 6 years) } \\
\hline Lesser gain & 39 & 13.4 & $32(81.6)$ & $7(18.4)$ & $2.71(1.15-6.41)$ & \\
\hline Higher gain & 251 & 86.6 & $156(62.0)$ & $95(38.0)$ & 1.00 & 0.02 \\
\hline \multicolumn{7}{|c|}{ Height/age (at birth) } \\
\hline Height deficit & 18 & 6.2 & 15 (83.3) & $3(16.7)$ & $2.91(0.82-10.3)$ & 0.08 \\
\hline Normal height & 272 & 93.8 & $172(63.2)$ & $100(36.8)$ & 1.00 & \\
\hline \multicolumn{7}{|c|}{ Height/age (6 years) } \\
\hline Height deficit & 85 & 29.3 & $64(75.0)$ & $21(25.0)$ & $1.93(1.09-3.41)$ & 0.02 \\
\hline Normal height & 205 & 70.7 & $125(60.8)$ & $80(39.2)$ & 1.00 & \\
\hline
\end{tabular}

*Pearson Chi-square test; CP: Cephalic perimeter

breastfeeding at six months of age and the presence of malocclusion, children who were not breastfed in the first semester of their lives were 2.19 times more likely to develop some type of occlusal anomaly at the age of six (95\%IC1.21-3.95).

After analyzing head circumference gains over the first six years of the children's lives, the children with lower gains were found to be approximately three times more likely to have malocclusion at six years of age $(\mathrm{OR}=2.93,95 \% \mathrm{IC} 1.16-7.39)$. Similar results were observed for child height. Children with stunting were twice as likely to have some occlusal abnormality (95\%IC 1.02-3.89).

Multivariate analysis revealed that the duration of pacifier use and the linear growth of the child are interdependent factors in determining the malocclusions of the children analyzed in this study.

\section{Discussion}

The results of this research reveal that factors related to growth, e.g. child $\mathrm{H} / \mathrm{A}$ ratio and gain in head circumference in the first six years of life, are associated with the development of malocclusions, independently of sucking habits, such as malocclusions resulting from duration of pacifier use. An analysis of these anomalies at this age should be conducted to investigate this finding further, evaluating not only local factors, e.g. sucking habits, but also growth-related factors.

The specific choice of studying six-year-old children is warranted by the marked sagittal growth of the face at this age, which is established in most children, as well as by changes in teething in this period. It must be borne in mind that tooth eruption occurs at this time, 
Table 4. Multivariate analysis of factors associated with malocclusions in children at six years old, in the Zona da Mata forest region of southern Pernambuco, Brazil, 2008.

\begin{tabular}{|c|c|c|c|c|c|c|c|}
\hline \multirow{3}{*}{ Variable } & \multirow{3}{*}{$\begin{array}{c}\text { Total } \\
n=290\end{array}$} & \multicolumn{6}{|c|}{ Malocclusions } \\
\hline & & \multicolumn{3}{|c|}{ Gross } & \multicolumn{3}{|c|}{ Adjusted } \\
\hline & & $\mathrm{n}=187$ & OR & $p$-value* & OR & $95 \% \mathrm{IC}$ & $p$-value* \\
\hline \multicolumn{8}{|l|}{ Model 1} \\
\hline \multicolumn{8}{|l|}{ Ceiling features } \\
\hline Concrete & 59 & 39 & 2.05 & 0.07 & 2.83 & $1.15-6.97$ & 0.08 \\
\hline Clay & 190 & 128 & 2.17 & & 2.48 & $1.17-5.29$ & \\
\hline Asbestos cement & 41 & 20 & 1.00 & & 1.00 & & \\
\hline \multicolumn{8}{|l|}{ Households - Refrigerator } \\
\hline No & 61 & 45 & 1.72 & & 1.62 & $0.81-3.26$ & 0.17 \\
\hline Yes & 229 & 142 & 1.00 & 0.09 & 1.00 & & \\
\hline \multicolumn{8}{|l|}{ Model 2} \\
\hline \multicolumn{8}{|l|}{ Breastfeeding (6 months) } \\
\hline None & 147 & 105 & 2.15 & 0.03 & 2.19 & $1.21-3.95$ & 0.32 \\
\hline Partial & 68 & 44 & 1.56 & & 1.49 & $0.74-2.97$ & \\
\hline Exclusive/Predominant & 75 & 40 & 1.00 & & 1.00 & & \\
\hline \multicolumn{8}{|l|}{ Model 3} \\
\hline \multicolumn{8}{|l|}{ Gain in $\mathrm{CP}$ ( 0 a 6 years) } \\
\hline Lesser growth & 39 & 32 & 2.71 & 0.02 & 2.93 & $1.16-7.39$ & 0.02 \\
\hline Greater growth & 251 & 156 & 1.00 & & 1.00 & & \\
\hline \multicolumn{8}{|l|}{ Height/age (6 years) } \\
\hline Height deficit & 85 & 64 & 1.93 & 0.02 & 2.00 & $1.02-3.89$ & 0.04 \\
\hline Normal height & 205 & 125 & 1.00 & & 1.00 & & \\
\hline \multicolumn{8}{|l|}{ Model 4} \\
\hline \multicolumn{8}{|l|}{ Bottle use (6 months) } \\
\hline Yes & 226 & 155 & 2.18 & 0.01 & 1.61 & $0.77-3.37$ & 0.20 \\
\hline No & 64 & 32 & 1.00 & & 1.00 & & \\
\hline \multicolumn{8}{|l|}{ Pacifier use duration } \\
\hline$<60$ months & 111 & 69 & 1.32 & 0.01 & 1.07 & $0.54-2.12$ & 0.01 \\
\hline$\geq 60$ months & 60 & 52 & 5.20 & & 4.45 & $1.80-10.9$ & \\
\hline None & 119 & 66 & 1.00 & & 1.00 & & \\
\hline
\end{tabular}

*Pearson Chi-square test; CP: Cephalic perimeter.

and that this eruption has a close relationship with occlusal harmony. According to Arboleda et al., ${ }^{19}$ the dimensions of the skull and the face of an individual at 6 years of age are the same at 18 years of age, in $94 \%$ and $84 \%$ of the cases, respectively. Several studies ${ }^{4,8,10,20,21}$ have used samples with a variable age range; however, studies involving children at different ages are difficult to compare, since growth rate and stage change with age.
It is noteworthy to observe that human evolution might have influenced the higher prevalence of malocclusion in modern populations. According to Lieberman, ${ }^{1}$ there has been a reduction in human head circumference throughout evolution. The findings of our study corroborate this statement, since a significant relationship with malocclusions was found in the association between $\mathrm{CP}$ at the age of six years and lowest $\mathrm{CP}$ gain over six years of life. 
According to Jaldin et al., ${ }^{22}$ breast milk may contribute to head circumference gain because of its nutrients; these authors demonstrated that exclusively breastfed children in the first six months of life showed a satisfactory increase in head circumference. However, this relationship was not confirmed in our study.

A significant association between absence of breastfeeding and malocclusion in the multivariate analysis was expected, since there was an association between this malocclusion and the nutritional status of the individual. However, children who were not breastfed were 2.19 times more likely to present occlusal abnormalities. It is reasonable to assume that not only the act of breast sucking, but also essential milk nutrients, are primarily responsible for the growth and development of an individual's ossification centers, and may thus contribute to poor dental and skeletal formations.

The breastfeeding categories were analyzed together due to the low rates of exclusive breastfeeding in the area studied..$^{13}$ These rates may have therefore resulted in a lower $\mathrm{CP}$ gain and in chronic malnutrition among the children of this sample. According to Thomaz and Valença, ${ }^{11}$ malnourishment results in delayed bone maturation, and can therefore be associated with a higher prevalence of malocclusion in children.

Even when pacifier use was controlled by the biological factors of the child, its use for five years or more was significantly associated with the presence of occlusal anomalies. The effect of pacifier use duration may have potentiated the establishment of these anomalies and favored early weaning. In fact, pacifier use may interfere negatively in the relationship between the supply and demand of milk, and may become a substitute for feeding, thus decreasing breastfeeding duration. ${ }^{23}$ However, the supply of pacifiers and bottles by parents could be related to cultural habits. Similar findings were reported in the study by Rochelle et al. ${ }^{23}$ and Gimenez et al. ${ }^{24}$

The literature also shows that the removal of a sucking habit before the age of five may naturally revert already installed occlusal abnormalities. ${ }^{2}$ However, this study revealed that if the individual has a status of compromised growth throughout life, the aforementioned abnormalities may develop.
Sucking habits developed from the use of pacifiers and bottle-feeding may interfere in facial development, but the nutritional status may also predict occlusal abnormalities in childhood.

A cross-sectional study with children between 3-5 years of age showed a higher prevalence of malocclusion among children whose mothers reported that their children did not have the habit of pacifier sucking, compared with those who did. ${ }^{22}$ These findings corroborate the hypothesis that the growth of a child explains the establishment of occlusal anomalies better than factors associated with sucking habits. However, these findings differ from those of most studies in the literature, which have reported sucking habits as the major determinants of the aforementioned anomalies in children., ${ }^{3,411}$ The design of this study may have favored the finding of this relationship. Cross-sectional studies provide a picture of the moment, and do not offer causality relationships, therefore not being true to reality. Furthermore, since the use of pacifiers and bottles is more notorious and habitual, these sucking habits are focused on more frequently in studies.

The lack of scientific studies assessing the association between nutritional status, through $\mathrm{H} / \mathrm{A}$ indexes and the gain in head circumference, and malocclusions in children, point out a yet unexplored aspect that emphasized the importance of giving greater credibility to the effects of child malnutrition on oral health.

Nutrition and growth are closely linked, considering that children do not reach their potential genetic growth if their basic nutritional needs are not met. ${ }^{25}$ Scientific evidence from studies using mice and pigs supports this association. The authors of these studies found that dietary deficiencies change the growth pattern of the skull and face, thus decreasing the available space for the teeth. ${ }^{26,27}$

On the other hand, longitudinal studies have losses during follow-up as a limitation; however, the percentage of loss of six-year-olds in this cohort was only $16.3 \%$. Because of the homogeneity of the sample characteristics, these losses barely interfered in the results, which yielded no statistical difference. These losses were mainly due to low socioeconomic status and job seasonality, a characteristic of the main 
economy developed in the region of the study. To deal with this problem, the present study introduced an analysis that used a proxy measure of SES ownership of a refrigerator and ceiling features. Nevertheless, use of this alternative did not lead to any important change in the associations.

It is noteworthy that the methodological issues of previous studies are unclear and difficult to interpret, because of confounding factors for malocclusion. Furthermore, we can highlight the inaccuracy of the outcome variable, because there are studies ${ }^{4,28,29}$ that propose the dependence on occlusion malformation, but that dwell on the issue of non-nutritive sucking habits, without underscoring the actual weight of these habits in relation to malocclusion, thus making the studies inconclusive.

However, this research improves the methodology of the studies conducted to date, because of both its high analytical power and its multivariate analysis plan, considering that the quality of the epidemiological information on this topic in the literature is mostly attributed to the analysis of cross-sectional studies.

Thus, the results presented in this study suggest caution in associating factors related to sucking habits with malocclusion in children, and also provide food for thought regarding the treatment to be implemented. Growth assessment is extremely important to identify an individual's health status, and is an indispensable tool for the prevention and early intervention of occlusal anomalies.

The promotion of an integrated and multidisciplinary prenatal and postnatal program of assistance that seeks to identify the factors involved in the growth and development of the child can help achieve early detection and prevention of childhood occlusal abnormalities. Our findings support the importance of a healthy diet starting at an early age as a way to receive oral health benefits.

\section{What this paper adds}

It brings a new approach to the factors associated with malocclusion and variables that are little explored in the literature. It reflects the influence of head and linear growth from early life up to six years of age on the establishment of child malocclusion.

\section{Why this paper is important to pediatric dentists}

This study emphasizes the importance of assessing linear growth by means of anthropometric measurement, such as head circumference and height/ age ratio, which seem to play an important role in the early prevention and intervention of malocclusions, and which monitor growth and child development.

\section{References}

1. Lieberman DE. Speculations about the selective basis for modern human craniofacial form. Evol Anthropol. 2008;17(1):55-68. https://doi.org/10.1002/evan.20154

2. Garib DG, Silva Filho $O G$, Janson G. Etiologia das más oclusões: perspectiva clínica (parte I)-fatores genéticos. Rev Clin Ortod Dental Press. 2010;9:77-97.

3. Jabbar NS, Bueno AB, Silva PE, Scavone-Junior H, Ferreira Ri. Bottle feeding, increased overjet and Class 2 primary canine relationship: is there any association? Braz Oral Res. 2011 Jul-Aug;25(4):331-7. https://doi.org/10.1590/S1806-83242011000400009

4. Romero CC, Scavone-Junior H, Garib DG, Cotrim-Ferreira

FA, Ferreira RI. Breastfeeding and non-nutritive sucking patterns related to the prevalence of anterior open bite in primary dentition. J Appl Oral Sci. 2011 Apr;19(2):161-8. https://doi.org/10.1590/S1678-77572011000200013
5. Nahás -Scocate ACR, Moura PX, Marinho RB, Alves AP, Ferreira RI, Guimarães FM. Association between infant feeding duration and the terminal relationships of the primary second molars. Braz J Oral Sci. 2011;10:140-5. https://doi.org/10.20396/bjos.v10i2.8641659

6. Evensen JP, Øgaard B. Are malocclusions more prevalent and severe now? A comparative study of medieval skulls from Norway. Am J Orthod Dentofacial Orthop. 2007 Jun;131(6):710-6. https://doi.org/10.1016/i.ajodo.2005.08.037

7. Ministério da Saúde (BR). Projeto SB Brasil 2010. Pesquisa Nacional de Saúde Bucal: resultados principais. Brasília, DF: Ministério da Saúde; 2011.

8. Montaldo L, Montaldo P, Cuccaro P, Caramico N, Minervini $G$. Effects of feeding on non-nutritive sucking habits and implications on occlusion in mixed dentition. Int J Paediatr Dent. 2011 Jan;21(1):68-73. https://doi.org/10.1111/j.1365-263X.2010.01092.x 
9. Diouf JS, Ngom PI, Badiane A, Cisse B, Ndoye C, Diop-Ba $\mathrm{K}$ et al. Influence of the mode of nutritive and non-nutritive sucking on the dimensions of primary dental arches. Int Orthod. 2010 Dec;8(4):372-85.

10. Thomaz EB, Cangussu MC, Silva AA, Assis AM. Is malnutrition associated with crowding in permanent dentition? Int J Environ Res Public Health. 2010 Sep;7(9):3531-44. https://doi.org/10.3390/ijerph7093531

11. Thomaz EB, Valença AM. Relationship between childhood underweight and dental crowding in deciduous teething. J Pediatr (Rio J). 2009 Mar-Apr;85(2):110-6. https://doi.org/10.1590/S0021-75572009000200005

12. Peres KG, Latorre MRO, Sheiham A, Peres MA, Victora CG, Barros FC. Social and biological early life influences on the prevalence of open bite in Brazilian 6-year-olds. Int J Paediatr Dent. 2007 Jan;17(1):41-9. https://doi.org/10.1111/j.1365-263X.2006.00793.x

13. Coutinho SB, Lira Pl, Lima MC, Ashworth A. Comparison of the effect of two systems for the promotion of exclusive breastfeeding. Lancet. 2005 Sep;366(9491):1094-100. https://doi.org/10.1016/S0140-6736(05)67421-1

14. Foster TD, Hamilton MC. Occlusion in the primary dentition: study of children at 2 and one-half to 3 years of age. Br Dent J. 1969 Jan;126(2):76-9.

15. Baume LJ. Physiological tooth migration and its significance for the development of occlusion: the biogenetic course of the deciduous dentition. J Dent Res. 1950;29(3):331-7. https://doi.org/10.1177/00220345500290031301

16. Angle EH. Classification of malocclusion. Dent Cosmos. 1899;41:248-64.

17. World Health Organization - WHO. Physical status: the use and interpretation of anthropometry. Geneva: World Health Organization; 1995.

18. Buschang PH. Class I malocclusions: the development and etiology of mandibular malalignments. Maryland: WB Saunders, 2014.

19. Arboleda C, Buschang PH, Camacho JA, Botero P, Roldan S. A mixed longitudinal anthropometric study of craniofacial growth of Colombian mestizos 6-17 years of age. Eur J Orthod. 2011 Aug;33(4):441-9. https://doi.org/10.1093/ejo/cjq099

20. Viggiano D, Fasano D, Monaco G, Strohmenger L. Breast feeding, bottle feeding, and non-nutritive sucking; effects on occlusion in deciduous dentition. Arch Dis Child. 2004 Dec;89(12):1121-3. https://doi.org/10.1136/adc.2003.029728
21. Kobayashi HM, Scavone Junior H, Ferreira RI, Garib DG. Relationship between breastfeeding duration and prevalence of posterior crossbite in the deciduous dentition. Am J Orthod Dentofacial Orthop. 2010 Jan;137(1):54-8. https://doi.org/10.1016/j.ajodo.2007.12.033

22. Jaldin MG, Pinheiro FS, Santos AM, Muniz NC, Brito LM. Crescimento do perímetro cefálico nos primeiros seis meses em crianças em aleitamento materno exclusivo. Rev Paul Pediatr. 2011;29(4):509-14. https://doi.org/10.1590/S0103-05822011000400007

23. Rochelle IM, Tagliaferro EP, Pereira AC, et al. Breastfeeding, deleterious oral habits and malocclusion in 5-year-old children in São Pedro, SP, Brazil. Dental Press J Orthod. 2010;15:71-81. https://doi.org/10.1590/S2176-94512010000200010

24. Gimenez CM, Moraes AB, Bertoz AP, Bertoz FA, Ambrosano $G B$. Prevalência de más oclusões na primeira infância e sua relação com as formas de aleitamento e hábitos infantis. Rev Dent Press Ortodon Ortop Facial. 2008;13(2):70-83. https://doi.org/10.1590/S1415-54192008000200009

25. Martins IS, Marinho SP, Oliveira DC, Araujo, EAC. Pobreza, desnutrição e obesidade: inter-relação de estados nutricionais de indivíduos de uma mesma família. Cienc Saúde Colet. 2007;12(6):1553-65. https://doi.org/10.1590/S1413-81232007000600017

26. Luke DA, Tonge CH, Reid DJ. Metrical analysis of growth changes in the jaws and teeth of normal, protein deficient and calorie deficient pigs. J Anat. 1979 Oct;129(Pt 3):449-57.

27. Alves AP, Dâmaso AR, Dal Pai V. The effects of prenatal and postnatal malnutrition on the morphology, differentiation, and metabolism of skeletal striated muscle tissue in rats. J Pediatr (Rio J). 2008 May-Jun;84(3):264-71. https://doi.org/10.1590/S0021-75572008000300013

28. Yonezu T, Kadoya M, Yakushiji M. Effects of prolonged breast- and bottle-feeding on occlusion characteristics in the primary dentition. Pediatric Dental Journal. 2005;15(2):176-9. https://doi.org/10.1016/S0917-2394(05)70049-5

29. Melink S, Vagner MV, Hocevar-Boltezar I, Ovsenik M. Posterior crossbite in the deciduous dentition period, its relation with sucking habits, irregular orofacial functions, and otolaryngological findings. Am J Orthod Dentofacial Orthop. 2010 Jul;138(1):32-40. https://doi.org/10.1016/j.ajodo.2008.09.029 